\title{
Culturally Relevant Protective and Risk Factors of Youth Risk Behaviors among Pakistani and Indian Students in Hong Kong: A Focus Group Study
}

\begin{abstract}
Purpose: The risk behaviors of Hong Kong ethnic minority students are understudied. This exploratory qualitative study aimed to explore culturally nuanced factors for the development and prevention of risk behaviors among Pakistani and Indian students in Hong Kong. Methods: Twenty-three students participated in four focus groups. All interviews were transcribed verbatim and analyzed using thematic analysis. Results: The participants reported bullying, delinquency, gambling, alcohol, cigarette, and drug uses as risk behaviors. Four themes emerged in the development and prevention of risk behaviors: (1) Parental and peer influence, and (2) an unsafe community environment were perceived by the participants as essential factors for the development of risk behaviors; and (3) Parental monitoring, and (4) strong religious beliefs were believed as protective factors for the prevention of risk behaviors. Conclusion: Further research and practice may investigate and focus on the factors embedded in the Hong Kong ethnic minorities' socio-cultural contexts to prevent risk behaviors.
\end{abstract}

Keywords: risk behaviors; South Asian youth; protective factors; risk factors; Hong Kong 


\section{Introduction}

Hong Kong, a previous British colony and current special administrative region of the People's Republic of China, encompasses diverse ethnic groups. There are 451,183 ethnic minorities (socalled non-Chinese individuals), constituting $6.4 \%$ of the whole population (about 7.3 million in mid-2015) in Hong Kong (Census and Statistics Department, 2011), such as Indonesians (1.9\%), Filipinos (1.9\%), Indians (0.4\%), Pakistanis (0.3\%), Nepalese (0.2\%). Among ethnic minorities in Hong Kong, a great number (86.7\%) of them were born out of Hong Kong and are generally from low-income families. Ethnic minorities are employed in low pay jobs compared to their Hong Kong Chinese counterparts in Hong Kong. For instance, employed female Thais and Indians and male Pakistanis are generally engaged in "elementary occupations" such as waitresses, and clerical workers (Census and Statistics Department 2011). To broaden these ethnic minorities' career aspirations, education plays an important role, especially in the Asian contexts.

In Hong Kong school settings, the number of ethnic minority students has been rising steadily since 2009/2010 to 2014/2015, reaching a total number of 15,600 by 2014/2015 (Kapai, 2015). Ethnic minority students generally display academic failure, low academic aspirations (Kennedy 2012; Kwok, Chiu, \& Lo, \& Wu, 2014) and/or poor acculturation (Lai, Gao, \& Wang, 2015). Such difficulties might be reinforced by the unique education system in Hong Kong. In brief, Hong Kong ethnic minority students studied in designated (segregated) schools under the public education system before 2014 where the medium of instruction was English and a lower standard compared to Chinese language component in the Chinese speaking schools was offered (Hue \& Kennedy, 2014). Since 2014, ethnic minority students are required to study in mainstream schools together with ethnic majority students so that they can be educated by the 
same curriculum and school climate mainly for academic achievement and social integration reasons (Hong Kong Unison, 2015), which can be considered an initial step for the promotion of positive youth development in ethnic minorities.

Existing studies on Hong Kong ethnic minority youth mostly seemed to examine their academic performance and the mass media emphasized that they are prone to displaying risk behaviors compared to the Hong Kong Chinese youth counterpart (Zhao, 2012). There are only a few existing studies on Hong Kong ethnic minority youth which has provided some relevant information on the prevalence of risk behaviors such as bullying and drug use $(\mathrm{Ku}, \mathrm{Chan}, \&$ Sandhu, 2005; the Polytechnic University of Hong Kong, 2012). Exploring young Hong Kong ethnic minorities' culturally specific risk and protective factors of youth risk behaviors may help promote culturally sensitive preventative services against the development of risk behaviors (Tang, 2014) which is important for the positive youth development.

In societies where the understanding of ethnic minority youths is more established, quantitative studies utilizing the Youth Risk Behavior Survey (YRBS) and Global School-based Health Survey (GSHS) are common (e.g., Coleman, Wileyto, Lenhart, \& Patterson, 2014) Pan \& Spittal, 2013). These studies generally found that family and school related factors (e.g., Pengpid \& Peltzer, 2012; Wang, Zhong, Fang, \& Wang, 2016) are associated with the development of adolescent risk behaviors, and healthy nutrition and being physically active are associated with the prevention of risk behaviors (e.g., Merrill \& Hanson, 2016). However, in places where the understanding of ethnic minority youths is less developed, exploratory qualitative studies are needed to explore the unique experiences of ethnic minority young people in depth to aid further studies and youth policy development (Sanders, Lankenau, \& Jackson-Bloom, 2010). Therefore, these surveys seem not to fully capture protective and risk factors of risk behaviors given these 
factors can change across cultures (Shin \& Kang, 2014). Hence, this qualitative study aimed to explore the possible culturally relevant protective and risk factors for the development and prevention of risk behaviors among Pakistani and Indian minority students in Hong Kong, and they consist of the largest proportion of the entire ethnic minority student population in Hong Kong (24.3\%) (Kapai, 2015).

\section{Methods}

\section{Participants}

The focus group method was adopted to help participants feeling comfortable to vocalize their insights in groups rather than individual interviews because of the shared similar experiences, for instance, perceived discrimination, of other group members (Parker \& Tritter, 2007). Therefore, we conducted four focus groups with 23 ethnic minority students residing in Hong Kong during February to June 2015. A purposive sampling strategy was used to recruit students who met the following criteria: aged 12-17 years; identified as either an Indian and a Pakistani origin; their parents who are ethnic minority; either same-race or interracial marriages (either Pakistani or Indian); low pay jobs of their parents; either Hong Kong born or foreign born; could speak English; and enrolled in secondary schools, to participate in this study.

Participants were recruited through social workers in two NGOs serving ethnic minority youth. The focus groups were conducted in these organizations at a convenient time for both the organizations and participants. The participants were briefed in advance about the purpose of the study, and conditions for their participation were discussed. Passive parental consent, informed consent, and permission for audio-recording were obtained. The focus groups were conducted in English and each lasted about an hour and a half. The Human Research Ethics Committee for Non-Clinical Faculties (EA271114) approved this study. 


\section{Design}

To assess for the eligibility for joining the focus groups, social workers of the two collaborating organizations used the screening questions to ask about the participants' age, the ethnicity of participants and their parents, the employment status and education background of their parents. We then conducted four focus groups with 23 eligible participants separately by gender and ethnicity to allow an in-depth exploration into ethnic minority students' perceptions and experiences about their risk behavior and related socio-cultural environment. Two assistants (a male Pakistani social worker and a female Burmese undergraduate student) also helped us for any language barriers and took notes during the interviews.

\section{Focus Group Process}

In each focus group interview, icebreaker questions were used to encourage participation, build rapport, and get to know each other (Knox, n.d.) in the first 15-20 minutes. These questions included "Could you name one thing you really like about yourself?", "What is the best thing happened to you this past week?", "What was the hardest thing you have ever done?", or "If you had this week over again what would you do differently?" (Knox, n.d.). This icebreaking stage helped the participants shared their insights openly about the sensitive subject of risk behaviors which indicates that they were confident with the interview situation and the setting. After that, we asked the following questions in the focus groups: (1) What do you think about your family, your school, your community, and your ethnic identity? (2) There is some news about youth risk behaviors (e.g., extensive alcohol and drug uses) in Hong Kong on TV and newspapers. What do you think about these? and (3) Have you heard anything about those risk behaviors in general, in

your school, or in your neighborhood or your community? Would you like to add more on risk behaviors if you think some of them are missing? 
Refreshments were provided at each focus group. At the conclusion of focus groups, each participant was provided with $\mathrm{HK} \$ 50$ for compensation of their time and travelling expenses. The participants were also informed that they would be referred to school practitioners if needed. However, no referral was needed after the participation of the study.

\section{Data Analysis}

We employed the following criteria for ensuring the rigor of qualitative study process, that is, credibility, transferability, dependability, and confirmability (Lincoln \& Guba, 1985) which may replace the internal and external validity, reliability, and objectivity in quantitative research (Denzin \& Lincoln, 1994). Each interview transcript was augmented with field notes illuminating self-reflexivity, including individual's feelings, concerns, and critique of role, possible biases, evaluate the research process, outcomes, and methods, also portray a summary of observations (Finlay, 2002; Hesser-Biber \& Leavy, 2006) and enhance trustworthiness of the qualitative study (Lietz \& Zayas, 2010). Our expertise in young individual's risk behaviors helped to ensure the transferability and dependability of this study. To perform the confirmability of the trustworthiness of the process of the methods and procedures of the present study, participants were recruited by the social workers in the NGOs based on the screening questions.

The first author transcribed the interviews. The first author examined the transcriptions against the audiotaped interviews, and inconsistencies were discussed with the two ethnic minority assistants until consensus was reached. The first author then deleted all personal identifiers including names, and places from the transcripts. Once all interviews were coded, the data were explored in-depth using the qualitative software analysis program NVivo 10. Thematic analysis was conducted based on familiarizing with data, generating initial codes, searching for themes, reviewing themes, defining and naming themes, and producing the report (Braun \& 
Clarke, 2006). Key words and responses were identified and highlighted from each interview transcript that formed themes. The authors discussed and agreed upon the themes.

\section{Results}

Table 1 displays the socio-demographic background of the participants. Thirteen participants were born in Hong Kong, and the remaining ten were born either in Pakistan or India. Low socioeconomic status (lower educational levels and parents' low pay jobs) was prevalent among the participants' families. Whereas all Indians expressed that they resided in culturally diverse neighborhoods, whereas Pakistani participants stated that they lived in segregated neighborhoods which could be diverse cultural traditions such as keeping strong ties with co-ethnic groups. Apart from two participants (one Pakistani and one Indian), others were enrolled schools with a high concentration of ethnic minorities.

Four themes that emerged from this study and the findings mostly reflected either participants' own experiences or perceptions they had about Pakistani or Indian young people:

\section{Parental and peer influence as risk factors leading to the development of risk behaviors}

This section is divided into two sub-sections. These are: development of risk behaviors and behaviors that participants consider a risk.

\section{a. Development of risk behaviors}

When responding to questions on perceptions about co-ethnic counterparts who engage in risk behaviors, participants emphasized parents' and peers' risk behaviors that could shape their behaviors. Four of the 23 participants (mean age=13, 2 female Pakistanis; male Indian, age 12; female Indian, age 14) talked about parental or extended family members' smoking behaviors. Two of them wondered aloud how parental risk behaviors influence children's potential risk taking behaviors: 
...their [peers] parents smoke. They think when their parents do this [smoking], they should follow them. Then they start smoking and eventually they become addicted (12-year-old male Indian adolescent)

...they [peers] also gamble because their fathers play cards even they are broke (12-year-old female Pakistani adolescent)

Participants also commented how peers could easily affect their behaviors:

...people in schools especially senior students drink or smoke... The others [peers] will also start smoking because of them... (13-year old female Indian adolescent)

Seven participants (mean age=15, 2 female Pakistanis; mean age $=17,2$ male Indians; mean age=17, 2 male Indians) talked about drug use in school settings. Their comments coalesced around the ideas that peers influence each other on risk behavior engagement and feasibility of reaching drugs:

In schools, they bring cupcakes and put drugs into them and sell to others (13-year-old female Pakistani adolescent)

...in schools...the students in our school, they learn from each other and start using drugs or smoking (13-year-old Indian male adolescent)

Two participants (female Pakistani, age 13 and male Indian, age 13) mentioned that their friends were involved in local illegal gambling stalls for gambling leading them to addiction. One of them made comment of gambling addiction:

My friends went to casino once. They won and they eventually became addicted (13-year-old male Indian adolescent)

Four participants (mean age=15, 2 female Indians and male Pakistani, age 17) stated that peers could influence their risk behaviors relative to alcohol use. For example, one Indian female adolescent commented:

...they [peers] take them [alcohol] home but their parents don't know...they drink at night while everybody falls asleep at home (15-year-old female Indian adolescent)

\section{b. Behaviors that participants consider a risk}


Cigarette use is common among school-going adolescents. One of the participants stated that accessing cigarettes is relatively easy due to its inexpensive price:

She [peer] smokes...she smokes cigarettes...she says it's so cheap. She bought it for HK\$2 [per cigarette]... (15-year-old female Indian adolescent)

Eleven participants (female Pakistani, age 13; mean age=15, 2 male Pakistanis; mean age=17, 2 male Indians; mean age=15, 2 female Indians) provided examples of experiences with gambling which may reflect the peer influence on such behaviors. For example, two of them stated that gambling exists in any kind of games in school settings:

In my school, my friend will play a game like paper and scissor... loser will give the winner HK\$5 (12-year-old male Pakistani adolescent)

There are some students...they bet ...they say let's play a game and bet for HK\$10... any kind of game. If somebody wins, the loser will give the other HK\$10 (17-year-old male Pakistani adolescent)

Especially one participant mentioned higher TV consumption because of being unsure of how to spend his spare time:

I watch TV for 17 hours because I have nothing to do (17-year-old male Pakistani adolescent)

Three participants talked about delinquency in terms of criminal behaviors in their community: ...some of my schoolmates beat a police officer and stole his phone (17-year-old male Pakistani adolescent)

Some students stole things from 7/11 or Wellcome [supermarket]... and brought them to school... they will share those things with us if we also steal (13-year-old male Indian adolescent)

I heard some people [schoolmates] steal and hide them in their pants (12-year old male Indian adolescent) 
Regarding bullying, various types of bullying have emerged in this study, including verbal bullying (e.g., calling mean names, calling names about race or religion, and easing in a hurtful ways), and physical bullying (e.g., hitting, kicking, pushing).

Some of the most striking comments during focus groups involved young people's (three participants) (mean age=15, 2 female Pakistanis and male Pakistani, age 17) descriptions of how they addressed bullying relative to name calling or humiliation based on their experiences. Here are two examples:

I was bullied at school when I was in form 3 [secondary school]...He made fun of me and called me "auntie auntie" (15-year-old female Pakistani adolescent)

I am sometimes bullied by Chinese people... they will say some bad words in Chinese (17year-old male Pakistani adolescent)

Two participants made comments about bullying that affect their academic achievement and mental health:

...bullying affects the students' academic performance badly (13-year-old female Pakistani adolescent)

A lot of kids... they consider suicide or self-harm when they are bullied (17-year-old male Indian adolescent)

Three participants (mean age=15, 2 male Pakistanis and female Pakistani, age 13) stated that bullying formed in teasing ethnic minorities' native languages. For example:

They [peers] make fun of our language ...We play football with Chinese people... when we speak in our native languages like 'pass the ball'...they [Chinese people] make fun of us... (17-year-old male Pakistani adolescent)

Two participants (mean age=13, 2 male Pakistanis) mentioned that having different skin color from the majority was another type of bullying. For instance:

In school, some Chinese people [peers] say that I am too black so they think I am not from Pakistan umm they say that I am from South Africa I feel bad (12-year-old male Pakistani adolescent) 
One of the participants commented that coming from less affluent family was the factor that lead bullying and cyberbullying:

...she was bullied on Facebook and they [peers] said bad things to her. She was even bullied in school because her parents were poor (15-year-old female Indian adolescent)

One participant stated that teasing harshly was another way of bullying:

Like teasing or threatening you that they will share your secret with others... (12-year old male Indian adolescent)

\section{Parental monitoring as a protective factor against the development of risk behaviors}

Three female participants (mean age=16, 3 female Indians) mentioned about parental monitoring on their whereabouts and social life that could prevent pregnancy as a resource for protection:

... too much freedom ...that will make you eventually get pregnant (17-year-old female Indian adolescent)

...I think they [parents] should be half open-minded and half strict because you know... too much of freedom can lead you to pregnancy (15-year-old female Indian adolescent)

One of the participants highlighted the importance of parents to protect her against gangsters in her neighborhood:

That's why my mother never lets me go outside because of...gangsters... (17-year-old female Indian adolescent)

3. Strong religious beliefs as protective factors against the development of risk behaviors

Four participants (mean age=16, 3 female Indians and male Indian, age 17) identified their religious beliefs as a potential protective factor against risk behavior engagement. For example:

...I'm a Muslim ... the things they teach us in our holy book...what you should do and what you should not do ... I think you would only get good deeds but you know acting against the holy book, you would get bad deeds... I like my religion. Because all the rules in my religion help me protect myself from boys (17-year-old female Indian adolescent, Muslim) Among same participants, religion was a protective factor against risk behaviors, including alcohol use, drug use, and smoking: 
...keep us safe from the bad things like alcohol (17-year-old male Indian adolescent, Buddhist); smoking (17-year-old male Indian adolescent, Buddhist); drugs (15-year-old female Indian adolescent, Buddhist)

...in our religion we are not allowed to drink (14-year-old female Indian adolescent, Muslim) 4. An unsafe community environment as a risk factor leading to the development of risk behaviors

Three participants stated that gangsters were present in their community where they identified their community as unsafe. Participants provided examples of unsafe community environment in terms of gangsters and how they protected themselves such as engaging in violence/abuse:

I was walking in an empty street ... there was one guy [Pakistani] who was staring at me... weird eyes and it was so scary ... my whole body was cold... eventually...umm he was trying to touch me... I kicked him... (17-year-old female Indian adolescent)

... he [Pakistani] is a gangster... he stares and scares us ... you know like attacking...I don't feel safe...I can see so many bad guys with weird faces...I just punch them... (15-year-old female Indian adolescent)

...It happened with a gangster [South Asian] just like when we [friends] were walking ... those gangsters were sitting behind us and then they start saying some bad words in our language... we replied back in bad words... (15-year-old female Indian adolescent)

\section{Discussion}

Though the topic of ethnic minorities' risk behaviors is increasingly discussed in the local mass media, this topic has not attracted much scholarly attention in the context of Hong Kong. Addressing this research gap will have significant research and practice implications for the positive youth development in ethnic minorities because this group of young people are expanding in size recently and they can become a significant societal asset in our society.

In this study, both Pakistani and Indian minorities reported a number of risk behaviors, namely, alcohol, drug, and cigarette uses, gambling, and delinquency. Few of them reported extensive TV consumption in contrast to existing studies which found that high levels of TV 
watching in ethnic minority youth in the United States (Eisemann, Bartee, \& Wang, 2012; Singh, Yu, Siahpush, \& Kogan, 2008). Bullying was one of the frequently reported risk behaviors. This study found, as have other studies (Pan \& Spittal, 2013; Srabstein \& Leventhal, 2010; Vervoort, Scholte, \& Overbeek, 2010) that ethnic minorities were more likely to be bullied (Ku et al., 2005) by co-ethnic, other ethnicities, or ethnic majorities in school settings. However, the findings varied according to gender and age of our participants. While younger females mentioned family members' smoking behaviors, older females reported bullying, risk for pregnancy, and alcohol use, drug use, and smoking. Younger males mentioned bullying relative to getting teased about their native languages and also skin color whereas older males reported drug use and peer influence on gambling as risk behaviours.

Four themes emerged pertaining to ethnic minority youth's risk behaviors in this study. These are: parental and peer influence as risk factors leading to the development of risk behaviors in both ethnic groups; parental monitoring as a protective factor against the development of risk behaviors only in Indians; strong religious beliefs as a protective factor against the development of risk behaviors only in Indians; and an unsafe community environment as a risk factor leading to the development of risk behaviors only in Indians. Both Indians and Pakistanis were more likely to be influenced by their parents' and peers' behaviors in this study align well with the empirical reviews documenting that parents and peers are significant role models in relation to the youth risk behavior engagement (Jackson, Sweeting, \& Haw, 2012; Simons-Morton \& Farhat, 2010).

Only Indians mentioned strong religious beliefs and parental monitoring on adolescents' behaviors as protective factors against the development of risk behaviors, and unsafe community environment as a risk factor leading to the development of risk behaviors in this study. Other 
quantitative studies have displayed that Indian young individuals' religious participation can be important in reducing risk behavior engagement such as alcohol or drug uses (Beebe et al., 2008; Kulis, Hodge, Ayers, Brown, \& Marsiglia, 2012). Similarly, several research studies have depicted that parental monitoring can be considered important in accounting for risk behaviors such as substance use and delinquency in Indian adolescents (Fosco, Stormshak, Dishion, \& Winter, 2012; Mmari, Blum, \& Teufel-Shone, 2010). An unsafe community context is also appeared to be salient among Indian youth in which they may be at heightened risk of engaging in risk behaviors (LaFromboise, Hoyt, Oliver, \& Whitbeck, 2006). In this study, participants stated that they responded in terms of violence (e.g., "... he was trying to touch me... I kicked him"). They may display these behaviors to mitigate the stressors they faced (Clark, Anderson, Clark, \& Williams, 1999). This is a critically important finding because it raises a new dimension in empirical studies to investigate the participants' risk behaviors in relation to the community context. Further research may focus on these individuals who could engage in aggressive behaviors (e.g., hitting) to protect themselves from risk behaviors in their distal environment.

In contrast, the aforementioned themes did not emerge in Pakistani youth. Pertaining to community context, this is possibly related to the fact that patriarchal society control and social cohesion are exerted more through families and segregated neighborhoods (Ali et al., 2011) than larger communities (Erni \& Leung, 2014). This may reflect that the role of neighborhood as a supervisor which may prevent Pakistani adolescents from engaging in risk behaviors. Pakistanis are mostly devoted Muslims. Although Islam generally bans alcohol and other substance uses which may prevent youth from risk behaviors (Shafiq et al., 2006), none of the participants mentioned religion as a protective factor against the reported risks in this study. While parents are aware of Pakistani youth's whereabouts, due to the possible lower restrictions on male 
adolescents in Pakistani culture, they can still display risk behaviors (Masood \& Sahar, 2014). Further, instead of being a protective factor in reducing risk behaviors, religion may not have a direct effect on risk behaviors (Parvizi, Aminizadeh, Sanagou, \& Sepahvand, 2009) due to other factors such as extensive urbanization or societal changes (Parvizy \& Ahmadi, 2009). Consequently, in this study, Pakistani minorities did not report any protective factors that may reduce risk behaviors. This may indicate that there could be other protective resources which may be relevant to Pakistani young people which were not covered in this study. Future studies may focus on other unobserved possible protective factors to prevent risk behaviors in Pakistani youth.

There are few limitations in this study. This was a small sample size of Hong Kong ethnic minority students. These findings should be interpreted with caution, as they may not be generalizable to a larger ethnic minority young population. Next, this study is confined to Pakistani and Indian school-going ethnic minorities. Future studies should target to focus on other ethnic groups (e.g., Indonesians, Filipinos) in Hong Kong in order to provide culturally competent school practice for the prevention of risk behaviors among ethnic minority youth in Hong Kong.

\section{Implications}

This study has research and practical implications. The findings of this study may shed light into further research to frame a larger quantitative study. This can be helpful for future studies to examine the culturally relevant risk and protective factors of risk behaviors in ethnic minority youth. Further studies can also investigate the local community and Hong Kong culture influences on ethnic minority students' experiences and/or perceptions that may trigger the development of risk behaviors or contribute to the prevention of such behaviors. Additionally, 
future research may focus on the gender and age differences in investigating the culturally relevant risk and protective factors of risk behaviors in ethnic minority young population.

In terms of practice, school nurses can teach parents and other school staff about the unhealthy risks for and healthy protective factors against the development of risk behaviors (Ahern \& Falsafi, 2013) to implement culturally nuanced school-based interventions. Given the great influence of social media (Black, Schmiege, \& Bull, 2013) on the development of adolescents' risk behaviors, nurses may use media outlet to raise the awareness of such behaviors and implement possible online prevention programs (Ahern, Kemppainen, \& Thacker, 2016; Creighton, 2010). Moreover, nurses may encourage these students about healthy/positive risktaking behaviors or sports (Ahern et al., 2016) relevant to their socio-cultural settings such as hiking, playing cricket which are widespread in South Asian population (O'Connor, 2010). Nurses may be informed by culturally responsive training (Saftner, Martyn, Momper, LovelandCherry, \&Low, 2015) about the prevention of risk behaviors in ethnic minority youth. The code of ethics of the Nursing Council of Hong Kong emphasizes the importance of trained culturally competent nurses to serve individuals with diverse ethnic backgrounds. A culturally responsive preventive model about the prevention of risk behaviors in ethnic minority youth via the collaboration of nurses with ethnic minority backgrounds and other professionals (Sobel, 2016) can be helpful. We strongly believe that the culturally competent nurses and school staff will contribute to the enhancement of ethnic minorities' academic achievement and positive school climate by the prevention of risk behaviors in Hong Kong school settings.

\section{References}


Abdi, T. A., Ruiter, R. A. C., \& Adal, T. A. (2015). Personal, social and environmental risk factors of problematic gambling among high school adolescents in Addis Ababa, Ethiopia. Journal of Gambling Studies, 31(1), 59-72. doi: 10.1007/s10899-013-9410-9

Ahern, N. R., \& Falsafi, N. (2013). Inhalant abuse: Youth at risk. Journal of Psychosocial Nursing and Mental Health Services, 51(8), 19-24. doi: 10.3928/02793695-20130612-02

Ahern, N. R., Kemppainen, J., \& Thacker, P. (2016). Awareness and knowledge of child and adolescent risky behaviors: A parent's perspective. Journal of Child and Adolescent Psychiatric Nursing, 29, 6-14. doi: 10.1111/jcap.12129

Ali, T. S., Krantz, G., Gul, R., Asad, N., Eva Johansson, E., \& Mogren, I. (2011). Gender roles and their influence on life prospects for women in urban Karachi, Pakistan: a qualitative study. Global Health Action, 4(7448). doi: 10.3402/gha.v4i0.7448

Åslund, C., \& Nilsson, K. W. (2013). Social capital in relation to alcohol consumption, smoking, and illicit drug use among adolescents: a cross-sectional study in Sweden. International Journal for Equity in Health, 12(33), 1-11. doi: 10.1186/1475-9276-12-33

Beebe, L. A., Vesely, S. K., Oman, R. F., Tolma, E., Aspy, C. B., \& Rodine, S. (2008). Protective assets for non-use of alcohol, tobacco and other drugs among urban American Indian youth in Oklahoma. Maternal and Child Health Journal, 12, 82-90. doi: $10.1007 / s 10995-008-0325-5$

Black, S. R., Schmiege, S., \& Bull, S. (2013). Actual versus perceived peer sexual risk behavior in online youth social networks. Translational Behavioral Medicine, 3(3), 312-319. doi:10.1007/s13142-013-0227-y

Blum, R. W., \& Nelson-Mmari, K. (2004). The health of young people in a global context. Journal of Adolescent Health, 35(5), 402-418. doi: 10.1016/j.jadohealth.2003.10.007 
Braun, V., \& Clarke, V. (2006). Using thematic analysis in psychology. Qualitative Research in Psychology, 3(2), 77-101.

Census and Statistics Department. (2011). Thematic Report: Ethnic Minorities. Retrieved from http://www.statistics.gov.hk/pub/B11200622012XXXXB0100.pdf

Charmaz, K., \& Belgrave, L. L. (2012). Qualitative interviewing and grounded theory analysis. In J. F. Gubrium, J. A. Holstein, A. B. Marvasti \& K. D. McKinney (Eds.), The SAGE handbook of interview research. The complexity of the craft (pp. 347-366). Thousand Oaks: CA: Sage.

Chau, R. C. M., \& Yu, S. W. K. (2001). Social exclusion of Chinese people in Britain. Critical Social Policy, 21(1), 103-125. doi: 10.1177/026101830102100103

Chui, W. H., \& Ling, H. W. H. (2013). School social work service in Hong Kong: The social work practitioner’s perspective In Wing Hong Chui (Ed.), School social work: Current practice and research (pp. 23-38). NY: Nova.

Chun, H., \& Mobley, M. (2014). The "immigrant paradox" phenomenon: assessing problem behaviors and risk factors among immigrant and native adolescents. The Journal of Primary Prevention, 35(5), 339-356. doi: 10.1007/s10935-014-0359-y

Clark, R., Anderson, N. B., Clark, V. R., \& Williams, D. R. (1999). Racism as a stressor for African Americans. American Psychologist, 54, 805-816.

Coleman, C., Wileyto, E. P., Lenhart, C. M., \& Patterson, F. (2014). Multiple health risk behaviors in adolescents: An examination of youth risk behavior survey data. American Journal of Health Education, 45(5), 271-277. doi: 10.1080/19325037.2014.933138

Cooper, S. M., Johnson, R. W., Griffin, C. B., Metzger, I., Avery, M., Eaddy, H., . . Guthrie, B. (2015). Community involvement and reduced risk behavior engagement among African 
American adolescents. The mediating role of empowerment beliefs. The Journal of Black Psychology, 41(5), 415-437. doi: 10.1177/0095798414536225

Creighton,C.(2010).Using social media to increase awareness of inhalant use. Journal of Communication in Healthcare, 3(3-4), 197-213.doi:10.1179/175380710×126882620

Cronley, C., White, H. R., Mun, E.-Y., Lee, C., Finlay, A., \& Loeber, R. (2012). Exploring the intersection of neighborhood racial and economic composition and individual race on substance use among male adolescents. Journal of Ethnicity in Substance Abuse, 11(1), 52-74. doi: 10.1080/15332640.2012.652526

Demanet, J., \& Van Houtte, M. (2014). Social-ethnic school composition and disengagement: An inquiry into the perceived control explanation. The Social Science Journal, 51(4), 659-675. doi: 10.1016/j.soscij.2014.09.001

Denzin, N., \& Lincoln, Y. (1994). Handbook of Qualitative Research. Thousand Oaks, CA: Sage Publications.

Dishion, T. J., Ha, T., \& Véronneau, M.-H. (2012). An ecological analysis of the effects of deviant peer clustering on sexual promiscuity, problem behavior, and childbearing from early adolescence to adulthood: An enhancement of the life history framework. Developmental Psychology, 48(3), 703-717. doi: 10.1037/a0027304

Education Bureau. (2015). Student Enrolment Statistics, 2014/15. (Kindergarten, Primary and Secondary Levels). Retrieved from http://www.edb.gov.hk/attachment/en/aboutedb/publications-stat/figures/Enrol_2014.pdf

Eisemann, J. C., Bartee, R. T., \& Wang, M. Q. (2012). Physical activity, TV viewing, and weight in the U.S. youth: 1999 Youth Risk Behavior Survey. Obesity Research, 10(5), 379-385. doi: 10.1038/oby.2002.52 
Ennett, S. T., Foshee, V. A., Bauman, K. E., Hussong, A., Faris, R., Hipp, J., . . McNaughton Reyes, H. L. (2008). The social ecology of adolescent alcohol misuse. Child Development, 79(6), 1777-1791. doi: 10.1111/j.1467-8624.2008.01225.x

Erni, J. N., \& Leung, L. Y.-m. (2014). Understanding South Asian minorities in Hong Kong. Hong Kong: Hong Kong University Press.

Fang, G. (2011). Linguistic capital: continuity and change in educational language polices for South Asians in Hong Kong primary schools. Current Issues in Language Planning, 12(2), 251-263. doi: 10.1080/14664208.2011.609687

Finlay, L. (2002). Negotiating the swamp: the opportunity and challenge of reflexivity in research practice. Qualitative Research, 2, 209-230. doi: 10.1177/146879410200200205

Fosco, G. M., Stormshak, E. A., Dishion, T. J., \& Winter, C. (2012). Family relationships and parental monitoring during middle school as predictors of early adolescent problem behavior. Journal of Clinical Child \& Adolescent Psychology, 41(2), 202-213. doi: 10.1080/15374416.2012.651989

Greaves, L., Johnson, J., Qu, A., Okoli, C. T. C., Hemsing, N., \& Barney, L. (2012). Gender identity, ethnic identity, and smoking among first nations adolescents. Journal of Aboriginal Health, 37-46.

Hesser-Biber, S. N., \& Leavy, P. (2006). The practices of qualitative research. Thousand Oaks, CA: Sage Publications.

Hong Kong Unison (2015). Submission to the panel on education of the legislative council on enhancing Chinese learning and teaching for non-Chinese speaking students. Retrieved from http://www.legco.gov.hk/yr14-15/english/panels/ed/papers/ed20150608cb4-1131-1e.pdf. 
Huang, R., Ho, S. H., Wang, M. P., Lo, W. S., \& Lam, T. H. (2016). Sociodemographic risk factors of alcohol drinking in Hong Kong adolescents. Journal of Epidemiology and Community Health, 70, 374-379. doi: 10.1136/jech-2015-206418

Hue, M. T., \& Kennedy, K. J. (2014). The challenge of promoting ethnic minority education and cultural diversity in Hong Kong: From policy to practice. Revista Espanola de Educacion Comparada, 23, 117-134.

Jackson, C., Sweeting, H., \& Haw, S. (2012). Clustering of substance use and sexual risk behaviour in adolescence: analysis of two cohort studies. BMJ Open, 2, e000661. doi: 10.1136/bmjopen-2011-000661

Kapai, P. (2015). The Education of Ethnic Minorities. Retrieved from http://www.law.hku.hk/ccpl/StatusofEthnicMinorities/J.Chapter3.pdf

Kennedy, K. J. (2012). The 'No Loser’ principle in Hong Kong's education reform: Does it apply to ethnic minority students? Hong Kong Teachers’ Centre Journal, 11, 1-23.

Kipping, R. R., Campbell, R. M., MacArthur, G. J., Gunnell, D. J., \& Hickman, M. (2012). Multiple risk behaviour in adolescence. Journal of Public Health, 34. doi: 10.1093/pubmed/fdr122

Knox, G. (n.d.). 40 Icebreakers for Small Groups. Retreived from https://insight.typepad.co.uk/40_icebreakers_for_small_groups.pdf

Ku, H.-B., Chan, K.-W., \& Sandhu, K. K. (2005). A Research Report on the Education of South Asian Ethnic Minority Groups in Hong Kong. Retrieved from http://www.cityu.edu.hk/youeprj/Download_area/resources/education\%20system\%20for \%20ethnic\%20minority\%20youths.pdf 
Kulis, S., Hodge, D. R., Ayers, S. L., Brown, E. F., \& Marsiglia, F. F. (2012). Spirituality and religion: Intertwined protective factors for substance use among urban American Indian youth. American Journal of Drug and Alcohol Use, 38(5), 444-449. doi: 10.3109/00952990.2012.670338

Kwok, S. S-.t., Chiu, C., Lo, B., \& Wu, R. (2014). Schooling and academic aspirations of South Asian students. SpringerPlus, 1, 1-2.

LaFromboise, T. D., Hoyt, D. R., Oliver, L., \& Whitbeck, L. B. (2006). Family, community, and school influences on resilience among American Indian adolescents in the Upper Midwest. Journal of Community Psychology, 34(2), 193-209. doi: 10.1002/jcop.20090

Lai, C., Gao, F., Wang, Q. (2015). Bicultural orientation and Chinese language among South Asian ethnic minority students in Hong Kong. International Journal of Bilingual Education and Bilingualism, 18(2), 203-224. doi: 10.1080/13670050.2014.887054

Lietz, C. A., \& Zayas, L. E. (2010). Evaluating qualitative research for social work practitioners. Advances in Social Work, 11(2), 188-202.

Lincoln, Y. S., \& Guba, E. G. (1985). Naturalistic inquiry. Beverly Hills, CA: Sage Publications Inc.

Masood, S., \& Sahar, N. U. (2014). An exploratory research on the role of family in youth's drug addiction. Health Psychology and Behavioral Medicine: An Open Access Journal, 2(1), 820-832. doi: 10.1080/21642850.2014.939088

McPherson, K. E., Kerr, S., Morgan, A., McGee, E., Cheater, F. M., McLean, J., \& Egan, J. (2013). The association between family and community social capital and health risk behaviours in young people: an integrative review. BMC Public Health, 13(971). doi: $10.1186 / 1471-2458-13-971$ 
Merrill, R. M., \& Hanson, C. L. (2016). Risk and protective factors associated with being bullied on school property compared with cyberbullied. BMC Public Health, 16(145). doi: 10.1186/s12889-016-2833-3

Mmari, K. N., Blum, R. W., \& Teufel-Shone, N. (2010). What increases risk and protection for delinquent behaviors among American Indian youth? Findings from three tribal communities. Youth \& Society, 41(3), 382-413. doi: 10.1177/0044118X09333645

O'Connor, P. (2010). Everyday hybridity and Hong Kong's Muslim youth. Visual Anthrology, 24(1-2), 203-225. doi: 10.1080/08949468.2011.528337

Pan, S. W., \& Spittal, P. M. (2013). Health effects of perceived racial and religious bullying among urban adolescents in China: a cross-sectional national study. Global Public Health, 8(6), 685-697. doi: 10.1080/17441692.2013.799218

Parker, A., \& Tritter, J. (2006). Focus group method and methodology: current practice and recent debate. International Journal of Research \& Method in Education, 29(1), 23-37. doi:10.1080/01406720500537304

Parvizi, S., Aminizadeh, K., Sanagou, A., \& Sepahvand, F. (2009). Exploring the concept of healthy family from adolescents’ perspectives in Zanjan. Iranian Journal of Nursing Research, 4, 7-17.

Parvizy, S., \& Ahmadi, F. (2009). A qualitative study on adolescence, health and family. Mental Health in Family Medicine, 6, 163-172.

Pengpid, S., \& Peltzer, K. (2012). Alcohol use and associated factors among adolescents students in Thailand. West Indian Medical Journal, 61(9), 890-896.

Reininger, B. M., Evans, A. E., Griffin, S. F., Sanderson, M., Vincent, M. L., Valois, R. F., \& Parra-Medina, D. (2005). Predicting adolescent risk behaviors based on an ecological 
framework and assets. American Journal of Health Behavior, 29(2), 150-161. doi: 10.5993/AJHB.29.2.6

Saftner, M. A., Martyn, K. K., Momper, S. L., Loveland-Cherry, C. J., \& Low, L. K. (2015). Urban American Indian adolescent girls: Framing sexual risk behavior. Journal of Transcultural Nursing, 26(4), 365-375. doi: 10.1177/1043659614524789

Sanders, B., Lankenau, S. E., \& Jackson-Bloom, J. (2010). Putting in work: Qualitative research on substance use and other risk behaviors among gang youth in Los Angeles. Substance Use \& Misuse, 45(5), 736-753. doi: 10.3109/10826081003595267

Shafiq, M., Shah, Z., Saleem, A., Siddiqi, M. T., Shaikh, K. S., Salahuddin, F. F., . . Naqvi, H. (2006). Perceptions of Pakistani medical students about drugs and alcohol: a questionnaire-based survey. Substance Abuse Treatment, Prevention, and Policy, 1(31). doi: 10.1186/1747-597X-1-31

Simons-Morton, B., \& Farhat, T. (2010). Recent findings on peer group influences on adolescent substance use. The Journal of Primary Prevention, 31(4), 191-208. doi: 10.1007/s10935010-0220-x

Singh, G. K., Yu, S. M., Siahpush, M., \& Kogan, M. D. (2008). High levels of physical inactivity and sedentary behaviors among US immigrant children and adolescents. Archives of Pediatrics and Adolescent Medicine Journal, 162(8), 756-763. doi: 10.1001/archpedi.162.8.756

Sobel, L. L. (2016). Guiding the process of culturally competent care with Hispanic patients: A grounded theory study. Journal of Transcultural Nursing, 27(3), 226-232. doi: $10.1177 / 1043659614558452$ 
Srabstein, J. C., \& Leventhal, B. L. (2010). Prevention of bullying-related morbidity and mortality: a call for public health policies. Bulletin of the World Health Organization, 88, 403-403. doi: 10.2471/BLT.10.077123

Sychareun, V., Thomsen, S., \& Faxelid, E. (2011). Concurrent multiple health risk behaviors among adolescents in Luangnamtha province, Lao PDR. BMC Public Health, 11(36). doi: 10.1186/1471-2458-11-36

Symons, C., Cinelli, B., James, T. C., \& Groff, P. (1997). Bridging student health risks and academic achievement through comprehensive school health programs. Journal of School Health, 67(6), 220-227. doi: 10.1111/j.1746-1561.1997.tb06309.x

Tang, W.-M. (2014). Examining the relationship between ethnicity and the use of drug-related services: an ethnographic study of Nepali drug users in Hong Kong. Substance Abuse and Rehabilitation, 5, 53-62. doi: 10.2147/SAR.S61885

The Polytechnic University of Hong Kong. (2012). Stand Up and Say Something! Retrieved from http://c4e.hkcss.org.hk/eng/research.php?n=5

Tong, H.-K., \& Goh, Y.-S. (2008). Challenges of Chinese language education in multi-lingual societies: Hong Kong and Singapore. International Education Studies, 1(4), 44-52.

Trucco, E. M., Colder, C. R., Wieczorek, W. F., Lengua, L. J., \& Hawk, L. W. (2014). Early adolescent alcohol use in context: How neighborhoods, parents, and peers impact youth. Development and Psychopathology, 26(2), 425-436. doi: 10.1017/S0954579414000042 
Tse, S., Zhu, S., Yu, C. H., Wong, P., Tsang, S. (2016). An ecological analysis of secondary school students' drug use in Hong Kong: A case-control study. International Journal of Social Psychiatry, 62(1), 31-40. doi: 10.1177/0020764015589132

Vervoort, M. H. M., Scholte, R. H. J., \& Overbeek, G. (2010). Bullying and victimization among adolescents: The role of ethnicity and ethnic composition of school class. Journal of Youth Adolescence, 39(1), 1-11. doi: 10.1007/s10964-008-9355-y

Viner, R. M., Haines, M. M. H., Head, J. A., Bhui, K., Taylor, S., Stansfeld, S. A., . . Booy, R. (2006). Variations in associations of health risk behaviors among ethnic minority early adolescents. Journal of Adolescent Health, 38(1), 55.e15-55.e23.

Voisin, D. R., DiClemente, R. J., Salazar, L. F., Crosby, R. A., \& Yarber, W. L. (2006). Ecological factors associated with STD risk behaviors among detained female adolescents. Social Work, 51(1), 71-79.

Wagenaar, A. C., Murray, D. M., Gehan, J. P., Wolfson, M., Forster, J. L., Toomey, J. L., . . . Jones-Webb, R. (2000). Communities mobilizing for change on alcohol outcomes from a randomized community trials. Journal of Youth \& Adolescence, 61(1), 85-94. doi: 10.15288/jsa.2000.61.85

Wang, M., Zhong, J.-M., Fang, L., \& Wang, H. (2016). Prevalence and associated factors of smoking in middle and high school students: a school-based cross-sectional study in Zhejiang Province, China. BMJ Open, 6, e010379. doi:10.1136/bmjopen-2015-010379

Wen, M., Van Duker, H., \& Olson, L. M. (2009). Social contexts of regular smoking in adolescence: towards a multidimensional ecological model. Journal of Adolescence, 32(3), 671-692. doi: 10.1016/j.adolescence.2008.06.008 
Wong, D. S. (2004). School bullying and tackling strategies in Hong Kong. International Journal of Offender Therapy and Comparative Criminology, 48(5), 537-553.

Wong, I. L. K., \& So, E. M. T. (2014). Internet gambling among high school studetns in Hong Kong. Journal of Gambling Studies, 30(3), 565-576. doi: 10.1007/s10899-013-9413-6

World Youth Report. (2013). WYR 2013 chapter one: The United Nations. Retrieved from http://www.unworldyouthreport.org/index.php?option=com_k2\&view=item\&layout=ite m\&id=81\&Itemid=223

Wu, L.-T., Woody, G. E., Yang, C., Pan, J.-J., \& Blazer, D. G. (2011). Racial/ethnic variations in substance-related disorders among adolescents in the United States. Archives of General Psychiatry, 68(11), 1176-1185. doi: 10.1001/archgenpsychiatry.2011.120

Zhao, S. (2012, July). Drug use on the fringes. TimeOut News. Retrieved from http://www.timeout.com.hk/bigsmog/features/51903/drug-use-on-the-fringes.htm 
Table 1. Demographic characteristics.

\begin{tabular}{|c|c|c|c|c|c|c|c|c|}
\hline & & \multicolumn{3}{|c|}{ Participant background } & \multicolumn{4}{|c|}{ Family background } \\
\hline & & Gender & Age & Birth place & $\begin{array}{l}\text { Mother educational } \\
\text { level }\end{array}$ & $\begin{array}{l}\text { Father educational } \\
\text { level }\end{array}$ & Mother occupation & Father occupation \\
\hline \multicolumn{9}{|c|}{ Focus group one } \\
\hline \multirow[t]{6}{*}{ Ethnicity } & Pakistani & Female & 13 & Pakistan & Primary & Primary & Housewife & Driver \\
\hline & Pakistani & Female & 12 & Pakistan & Primary & Secondary & Housewife & Driver \\
\hline & Pakistani & Female & 15 & Pakistan & Primary & Secondary & Housewife & Driver \\
\hline & Pakistani & Female & 17 & Hong Kong & Secondary & Primary & Housewife & Driver \\
\hline & Pakistani & Female & 16 & Hong Kong & Secondary & Primary & Housewife & Driver \\
\hline & Pakistani & Female & 13 & Hong Kong & Secondary & Primary & Housewife & Driver \\
\hline \multicolumn{9}{|c|}{ Focus group two } \\
\hline \multirow[t]{6}{*}{ Ethnicity } & Pakistani & Male & 15 & Hong Kong & No schooling & Primary & Housewife & Worker* \\
\hline & Pakistani & Male & 14 & Hong Kong & No schooling & Primary & Housewife & Worker* \\
\hline & Pakistani & Male & 12 & Pakistan & Secondary & Secondary & Housewife & Worker* \\
\hline & Pakistani & Male & 16 & Hong Kong & No schooling & Secondary & Housewife & Worker* \\
\hline & Pakistani & Male & 15 & Hong Kong & Secondary & Secondary & Housewife & Driver \\
\hline & Pakistani & Male & 17 & Hong Kong & No schooling & Secondary & Housewife & Worker* \\
\hline \multicolumn{9}{|c|}{ Focus group three } \\
\hline \multirow[t]{3}{*}{ Ethnicity } & Indian & Female & 16 & India & Secondary & Secondary & Housewife & Worker* \\
\hline & Indian & Female & 15 & Hong Kong & Secondary & Secondary & Waitress & Worker* \\
\hline & Indian & Female & 15 & Hong Kong & Secondary & Secondary & Waitress & Worker* \\
\hline
\end{tabular}




\begin{tabular}{|c|c|c|c|c|c|c|c|}
\hline Indian & Female & 14 & Hong Kong & College & College & Housewife & Worker* \\
\hline $\begin{array}{l}\text { Indian } \\
\text { Focus group four }\end{array}$ & Female & 17 & Hong Kong & Primary & Primary & Housewife & Worker* \\
\hline Indian & Male & 12 & India & Secondary & Secondary & Waitress & Worker* \\
\hline Indian & Male & 17 & India & Secondary & Secondary & Housewife & Worker* \\
\hline Indian & Male & 17 & India & No schooling & Illiterate & Waitress & Worker* \\
\hline Indian & Male & 17 & India & Secondary & Secondary & Waitress & Driver \\
\hline Indian & Male & 13 & India & College & Secondary & Waitress & Worker \\
\hline
\end{tabular}

Note. *waiter, clerk, deliveryman, construction worker 